\title{
Octopamine Mediates Thermal Preconditioning of the Locust Ventilatory Central Pattern Generator via a cAMP/Protein Kinase A Signaling Pathway
}

\author{
Gary A. B. Armstrong, Kelly L. Shoemaker, Tomas G. A. Money, and R. Meldrum Robertson \\ Department of Biology, Queen's University, Kingston, Ontario, Canada K7L 3N6
}

We investigated the role of biogenic amines in generating thermoprotection of the ventilatory motor pattern circuitry in Locusta migratoria. Levels of octopamine $(\mathrm{OA})$ and dopamine $(\mathrm{DA})$ in the metathoracic ganglion decreased during heat stress. We measured the thermosensitivity of central pattern generation in response to a ramped increase of temperature in semi-intact preparations. $0 \mathrm{~A}, \mathrm{DA}$, and tyramine (TA) were either bath applied or injected into the locust hemocoel 4-8 h before testing. Neither TA nor DA modified the thermotolerance of ventilatory motor pattern generation. However, $\mathrm{OA}$ treatment by bath applications $\left(10^{-4} \mathrm{M} \mathrm{OA}\right)$ or by injections into the hemocoel $(2 \mu \mathrm{g} / 10 \mu \mathrm{l} \mathrm{OA})$ mimicked heat shock preconditioning and improved the thermotolerance of the motor pattern by increasing the failure temperature and by decreasing the time taken to recover operation after a return to room temperature. Heat shock-induced thermoprotection was eradicated in locusts preinjected with epinastine ( $0 c t \beta R$ antagonist). Neuropil injections of the cAMP agonist and protein kinase A (PKA) activator, Sp-cAMPs, both conferred thermoprotection in control locusts and rescued thermoprotection in epinastine-treated HS locusts. Similar injections of the PKA inhibitor Rp-cAMPs blocked the thermoprotective effect of bath-applied 0A. Octopamine-mediated thermoprotection was also abolished with neuropil injections of cycloheximide or actinomycin $\mathrm{D}$, indicating a requirement for transcription and translation. We conclude that $\mathrm{OA}$ has a crucial role in triggering protein synthesisdependent physiological adaptations to protect CNS function during heat stress by activating a cAMP/PKA pathway.

Key words: insect; heat shock; temperature; thermotolerance; motor pattern; biogenic amine; cAMP; PKA

\section{Introduction}

Impaired CNS function during hyperthermia can have severe fitness consequences, and animals have evolved several mechanisms to cope with heat stress. Unlike homeotherms, which can physiologically regulate body temperature during ambient temperature fluctuation, poikilotherms such as the locust (Locusta migratoria) must endure more extreme internal temperature changes. These animals are thus well suited for the investigation of physiological adaptations that have evolved to protect nervous systems from heat stress. Preconditioning locusts with a high $\left(45^{\circ} \mathrm{C}\right)$ and prolonged $(3 \mathrm{~h})$ exposure to heat followed by a $1 \mathrm{~h}$ recovery [heat shock treatment (HS)] induces thermotolerance in particular tissues including the CNS (Robertson et al., 1996).

Abdominal ventilatory movements in locusts are controlled by a central pattern generator (CPG) located in the metathoracic ganglion (MTG) (Bustami and Hustert, 2000). Cycle frequency increases with increasing temperature from $\sim 1 \mathrm{~Hz}$ at room temperature to $2.5-3.0 \mathrm{~Hz}$ at $45^{\circ} \mathrm{C}$. Motor pattern generation fails at

\footnotetext{
Received Aug. 3, 2006; revised Sept. 15, 2006; accepted 0ct. 8, 2006.

This work was supported by the Natural Sciences and Engineering Research Council of Canada. We thank Boehringer Ingelheim for their generous gift of epinastine, Adam Szulewski for collecting HPLC data, and R. David Andrew for his comments on a previous version of this manuscript.

Correspondence should be addressed to Gary A. B. Armstrong at the above address. E-mail: armstrog@ biology.queensu.ca.

DOI:10.1523/JNEUROSCI.3347-06.2006

Copyright $\odot 2006$ Society for Neuroscience $\quad$ 0270-6474/06/2612118-09\$15.00/0
}

high temperatures (Newman et al., 2003). Thermotolerance of the circuit can be improved by stress preconditioning using heat shock, anoxia, or cold shock and is mimicked by bath application of serotonin (Newman et al., 2003). At the moment of heatinduced rhythm failure, there is an abrupt rise in extracellular potassium $\left[\mathrm{K}^{+}\right]_{\mathrm{o}}$ in the MTG from $\sim 11$ to $>40 \mathrm{mM}$; recovery of the rhythm is reliably associated with time-dependent restoration of the $\left[\mathrm{K}^{+}\right]_{\mathrm{o}}$ gradient with HS locusts showing more rapid recovery (Robertson, 2004). The mechanisms that coordinate such HS-mediated thermotolerance are unknown, and a possibility we examine here is that amines such as octopamine (OA) are involved.

Octopamine is an important invertebrate neurotransmitter (Nathanson, 1979), neuromodulator (Lange and Orchard, 1986), and neurohormone (Orchard 1982), generating an arousal response in invertebrates (Kravitz and Huber, 2003) similar to norepinephrine in vertebrates (Roeder, 1999, 2005). In the insect CNS, OA is one of the most abundant amines, having a concentration much higher than tyramine (TA) and at least two to three times greater than dopamine (DA) (Evans, 1985). High concentrations of OA $(170 \mathrm{~nm})$ have been reported in L. migratoria hemolymph (Orchard et al., 1981), along with similar concentrations (49 nM) found in Schistocerca americana gregaria (Davenport and Evans, 1984). OA is known to modulate many motor patterns, including foregut activity (Zilberstein et al., 2004), walking and flying (Sombati and Hoyle, 1984), and ventilation 
(Bellah et al., 1984; Ramirez and Pearson, 1989). Levels of OA in locust hemolymph have been observed to increase after various stresses (e.g., heat, cold, mechanical and chemical stress) and in some instances as much as a 10 -fold increase from original levels has been observed (Davenport and Evans, 1984). In the insect CNS, $\beta$-adrenergic-like octopamine receptors (Oct $\beta$ Rs) are coupled via G-proteins to adenylyl cyclase, giving rise to an increase in cAMP that results in modulation of motor patterns (Bellah et al., 1984; Sombati and Hoyle, 1984). Here, we show that OA mediates HS-induced thermoprotective changes via a cAMP/ protein kinase A (PKA) signaling pathway and protein synthesis.

\section{Materials and Methods}

Animals

Adult male locusts, Locusta migratoria, 4-6 weeks postimaginal moult, were collected from a crowded colony maintained in the Biology Department at Queen's University. Animals were housed under a $12 \mathrm{~h}$ light/dark cycle. Light-time and dark-time cage temperatures were $25 \pm 1$ and $21 \pm$ $1{ }^{\circ} \mathrm{C}$, respectively, and humidity was constant at $23 \pm 1 \%$. All animals were collected from the colony at the same time each morning and were weighed and placed in a well ventilated $2 \mathrm{~L}$ polyethylene container. Only animals that weighed $1.75 \pm 0.25 \mathrm{~g}$ were used for experimentation. All electrophysiological recordings were taken $4-8 \mathrm{~h}$ after locusts were collected from the colony.

\section{Heat shock}

Locusts designated for control (Con) and heat shock treatments were separated into different containers. HS animals were placed in a humid incubator for $3 \mathrm{~h}$ at $45^{\circ} \mathrm{C}$ followed by a $1-5 \mathrm{~h}$ recovery at room temperature $\left(\sim 21^{\circ} \mathrm{C}\right)$; Con animals were held at room temperature for $4-8 \mathrm{~h}$.

\section{HPLC}

For both OA and DA assays, animals were $3-5$ weeks postimaginal moult at the time of treatment and dissection. Ganglia were collected at different times during HS treatment, ranging from 5 to $60 \mathrm{~min}$ after entering the incubator. Immediately after removal from the incubator, the wings, legs, and pronotum were removed from the animal, and a dorsal midline incision was made. The gut and overlying tissues were dissected out, and the MTG was quickly removed by cutting the connectives midway between the MTG and the abdominal ganglion (A4) and midway between the MTG and mesothoracic ganglion. All other nerve roots arising from the MTG were cut distally to prevent loss of ganglionic contents. The MTG was rinsed with cold standard locust saline, blotted dry on a clean lint-free wipe, and submerged in $100 \mu \mathrm{l}$ of ice-cold $0.2 \mathrm{~N}$ perchloric acid (Sigma-Aldrich, Oakville, Ontario, Canada). Each dissection took $\sim 5$ min to complete.

Samples were sonicated individually for $5-10 \mathrm{~s}$ using a probe sonicator (VirSonic 60; VirTis, Gardiner, NY). Homogenized samples were then centrifuged at $15,000 \mathrm{rpm}$ for $30 \mathrm{~min}$ at $4^{\circ} \mathrm{C}$. The supernatant was collected and frozen at $-80^{\circ} \mathrm{C}$ for no longer than 1 week. To prepare for HPLC, samples were thawed and mixed with $100 \mu \mathrm{l}$ of mobile phase and were processed through a $0.22 \mu \mathrm{m}$ centrifugal filter unit (Millipore, Etobicoke, Ontario, Canada) at 15,000 rpm for $11 \mathrm{~min}$ at $4^{\circ} \mathrm{C}$. Mobile phase consisted of $9 \%$ acetonitrile, $15 \%$ methanol, $5 \mathrm{~mm}$ citric acid, $75 \mathrm{~mm}$ sodium phosphate monobasic, and $2.1 \mathrm{~mm}$ sodium dodecyl sulfate, all dissolved in HPLC-grade water. $\mathrm{pH}$ was adjusted from 6.05-6.75 using concentrated sodium hydroxide.

Samples were manually injected onto an Inertsil C18 column (150A/ OD52, $15 \times 0.46 \mathrm{~cm}, 5 \mu \mathrm{m}$; CSC Chromatography Sciences, Montreal, Quebec, Canada) and were detected electrochemically on a singlechannel amperometric detector (Intro, VT-03 electrochemical flowcell; Antec Leyden, Zoeterwoude, The Netherlands) set at $0.75 \mathrm{~V}$ for both amines. Temperature was constant at $30^{\circ} \mathrm{C}$. Mobile phase was first filtered and degassed through a $0.22 \mu \mathrm{M}$ filter (Pall, Ann Arbor, MI) and was pumped isocratically at $0.8 \mathrm{ml} / \mathrm{min}$ (LC-10ADVP pump; Shimadzu, Tokyo, Japan). The putative peak of interest was initially identified on the basis of retention time compared with a known standard and was further confirmed on the basis of changes in peak size and/or retention time in response to changes in applied channel voltage, percentage organics, and
$\mathrm{pH}$. Integration of peaks was performed using a Shimadzu C-R5A Chromatopac Integrator, and calibration of peak size was conducted by injecting standards of known concentration. Fresh standards were run daily.

\section{Semi-intact preparation}

A semi-intact preparation (Robertson and Pearson, 1982) was used to access the nervous system for electrophysiology. A dorsal midline incision was made from the fifth abdominal segment to the head. Animals were pinned ventral-side down, and gut and overlying tissues were removed exposing the ventral nerve cord. Nerve 5 of the MTG was cut on both sides allowing saline and pharmacological agents to permeate the ganglion. A peristaltic pump (Peri-Star; World Precision Instruments, Sarasota, FL) superfused the thoracic and abdominal cavities with standard locust saline (in mm: $147 \mathrm{NaCl}, 10 \mathrm{KCl}, 4 \mathrm{CaCl}_{2}, 3 \mathrm{NaOH}, 10 \mathrm{HEPES}$ buffer, $\mathrm{pH}$ 7.2). Saline flow originated at the head-thorax junction and exited through an incision in the abdominal wall. Flow rate was constant at $5 \mathrm{ml} / \mathrm{min}$.

\section{Electromyographic recording of the motor pattern}

Motor patterns were recorded using an electromyographic (EMG) electrode made from $0.1 \mathrm{~mm}$ diameter copper wire, insulated except at the tip, and positioned on the abdominal expiratory muscle 161 (Newman et al., 2003). Signals were amplified using a model P15 Preamplifier (Grass Instruments, West Warwick, RI) and digitized using a Digidata 1200 (Molecular Devices, Union City, CA). Data were analyzed using ClampFit 9.0 ( Molecular Devices). Preparations were bathed for $1 \mathrm{~h}$ with saline before starting the temperature ramp, allowing for any pharmacological treatments to have an effect and for the ventilatory rhythm to stabilize. Saline temperature was controlled by passing current through a Nichrome wire wrapped around an insulated glass pipette. Temperature was monitored using a thermocouple (BAT-12; Physitemp Instruments, Clifton, NJ) placed next to the MTG. Temperature was ramped up $5^{\circ} \mathrm{C} /$ min starting at room temperature $\left(\sim 21^{\circ} \mathrm{C}\right)$ until failure of the motor pattern. At this time, the heater was switched off permitting the saline temperature to return to ambient levels and allowing the motor pattern to recover.

Failure temperature $\left({ }^{\circ} \mathrm{C}\right)$ and recovery time (seconds) were scored as the temperature at which all electrical activity from the muscle ceased and the length of time taken to recover motor pattern function. We also monitored the percentage of preparations that exhibited arrhythmias. We defined an arrhythmia as a ventilatory cycle with a burst duration two times longer than that of the preceding burst duration and a pause in the ventilatory rhythm for at least double the period of the preceding cycle. We also measured cycle frequency (hertz), burst duration (milliseconds), and duty cycle (duration per period) of the motor pattern during temperature ramps. Data were plotted using SigmaPlot 8.0 (SPSS, Chicago, IL).

\section{Intracellular recording}

Intracellular recordings of ventilatory interneurons were made using sharp microelectrodes (1 M KAc, 40-60 M 2 ) and amplified using a model 1600 Neuroprobe amplifier (A-M Systems, Carlsborg, WA). Neurons were identified based on their phase relationship to the EMG signal as either inspiratory $(n=3)$ or expiratory $(n=10)$. Of all impalements, seven were successfully recorded throughout the temperature ramp until failure.

\section{Pharmacology}

Before testing the effects of temperature, $\mathrm{OA}$ and the $\mathrm{Oct} \beta \mathrm{R}$ antagonist epinastine (EP) were bath applied in semi-intact preparations, and the cycle frequency $(\mathrm{Hz})$ of the ventilatory motor pattern was monitored. Drugs were dissolved in standard locust saline and superfused over the MTG for $20 \mathrm{~min}$. OA-treated animals received $10^{-5} \mathrm{M}, 10^{-4} \mathrm{M}$, and $10^{-3} \mathrm{M}$, whereas EP-treated locusts received bath applications of $10^{-6} \mathrm{M}$. Motor pattern changes were also monitored after an extended exposure (1 h) of $10^{-4} \mathrm{M} \mathrm{OA}, \mathrm{DA}$, and TA.

To examine whether OA and other amines could generate thermotolerance in the CNS, short bath applications were applied to HS and Con locusts before the temperature ramp. Concentrations of either $10^{-4} \mathrm{M}$ or $10^{-3} \mathrm{M}$ OA were applied $20 \mathrm{~min}$ before thermotolerance testing. In a 
second set of experiments, extended $1 \mathrm{~h}$ treatments with $10^{-4} \mathrm{M} \mathrm{OA}$ or TA were bath applied. Neurohormonal effects of OA and DA were investigated by injecting $2 \mu \mathrm{g} / 10 \mu \mathrm{l}$ of OA, DA, or EP into the hemocoel of intact locusts. Animals in the untreated comparison groups (HS and Con) received sham injections of standard locust saline. Locusts receiving injections of amines were superfused with standard locust saline for $1 \mathrm{~h}$ in the semi-intact preparation, and individuals receiving the $1 \mathrm{~h}$ bath application of amines were given sham injections of saline before dissection. Injections were given $4-8 \mathrm{~h}$ before testing thermotolerance.

We pharmacologically manipulated cAMP levels in the MTG by treating locusts with a $1 \mathrm{~h}$ bath application of $10^{-5} \mathrm{M}$ forskolin (FOR), a potent activator of adenylyl cyclase. FOR was dissolved in $10 \mu \mathrm{l}$ of DMSO before dilution in standard locust saline. Sham injections also contained $10 \mu \mathrm{l}$ of DMSO.

To locally modulate activity of PKA, we pressure-injected using a PicoSpritzer III (INTRACEL, Shepreth, UK) small volumes $(70 \mathrm{nl})$ of either $10^{-4}$ M Sp-adenosine $3^{\prime}, 5^{\prime}$-cyclic monophosphorothioate triethylammonium salt (Sp-cAMPs), an analog of cAMP and activator of PKA, or $10^{-4} \mathrm{M}$ Rp-adenosine 3',5' -cyclic monophosphorothioate triethylammonium salt (Rp-cAMPs), a deactivator of PKA. Drugs were injected into the ventilatory neuropil every 5 or $10 \mathrm{~min}$ over $50 \mathrm{~min}$. Ten minutes after the last injection, we tested thermotolerance. Both SpcAMPs and Rp-cAMPs were first dissolved in $10 \mu \mathrm{l}$ of DMSO, before dilution in standard locust saline. Sham injections of locust saline contained $10 \mu \mathrm{l}$ of DMSO.

To test whether elements of the octopaminergic signaling pathway were interacting with the genome to confer thermoprotection, we arrested transcription and translation with $10^{-6} \mathrm{M}$ actinomycin D (ACTD) and $10^{-6} \mathrm{M}$ cycloheximide (CHX), respectively, during a $1 \mathrm{~h}$ bath application of $10^{-4} \mathrm{M} \mathrm{OA}$ (a treatment previously shown to induce thermotolerance). ACTD and CHX (70 nl) were injected into the neuropil every $10 \mathrm{~min}$ (five times over $50 \mathrm{~min}$ ). Ten minutes after the final injection, we tested thermotolerance. ACTD and CHX were both dissolved in $10 \mu \mathrm{l}$ of ethanol before further dilution in standard locust saline. Sham injections of standard locust saline contained the same concentration of ethanol.

\section{Potassium clearance}

To test the ability to regulate $\left[\mathrm{K}^{+}\right]_{\mathrm{o}}$, we pressure-injected small volumes $(150 \mathrm{nl})$ of locust saline containing elevated levels of $\mathrm{K}^{+}$(in mM: 147 $\mathrm{NaCl}, 150 \mathrm{KCl}, 4 \mathrm{CaCl}_{2}, 3 \mathrm{NaOH}, 10$ HEPES buffer, $\mathrm{pH}$ 7.2) into the ventilatory neuropil to arrest rhythm generation. We measured the length of time required to restore rhythm generation in Con, OA $(1 \mathrm{~h}$ bath application $\left.10^{-4} \mathrm{M}\right), \mathrm{HS}$, and EP-injected HS locusts.

\section{Drugs}

Chemicals were obtained from Sigma-Aldrich. The Oct $\beta R$ antagonist EP was a generous gift from Boehringer Ingelheim (Biberach, Germany).

\section{Statistical analyses}

HPLC. Animals were always run as matched pairs. That is, Con and HS animals were always dissected and processed by HPLC-ED together. All samples were ultimately calculated as "picograms per ganglion" using standard curves generated by injecting standards of known quantity. The samples were normalized to the Con of the pair. The graph of HPLC shows the Con value as 1 with no variability, whereas HS samples are described using the median and quartiles. Nonparametric statistics were applied as appropriate.

Thermotolerance. Statistically significant differences between treatments were assessed by performing one-way or two-way repeated measures-ANOVA (RM-ANOVA) followed by a multiple comparison (Tukey's) test. Treatment groups tested for thermotolerance $4-8 \mathrm{~h}$ after injections into the hemocoel were first grouped into $1 \mathrm{~h}$ intervals $(4,5,6$, 7 , and $8 \mathrm{~h}$ ). A Pearson correlation test showed no significant differences between these groups, and the data were pooled into one large group $(4-8 \mathrm{~h})$. All data are reported as mean \pm SE. Data were analyzed using SigmaStat 3.1.1 (SPSS).

\section{Results}

\section{Heat shock depletes octopamine and dopamine in the metathoracic ganglion}

Octopamine and dopamine were resolved as well-defined peaks in HPLC chromatograms (Fig. $1 A$ ) with control levels of $\sim 1.5 \mu \mathrm{g}$ of OA and $500 \mathrm{ng}$ of DA per MTG. We found a modest but significant decrease (Mann-Whitney; $u=245 ; n=15 ; p=$ 0.056 ) in the relative quantity of OA from 100 to $90 \%$ after $15 \mathrm{~min}$ of heat shock (Fig. $1 \mathrm{~B}$ ). Levels returned to pre-HS values by 30 min. We also found a modest but significant decrease (MannWhitney; $u=245 ; n=14 ; p=0.056$ ) in the relative quantity of DA from 100 to $92 \%$ after 15 min of HS. Levels returned to $100 \%$ by $30 \mathrm{~min}$.

\section{Octopamine, but not dopamine or tyramine, acutely increases ventilatory rhythm frequency}

To examine the excitatory neuromodulatory effects of OA on the ventilatory rhythm, various concentrations were superfused over the MTG. OA treatment did not disrupt rhythm generation (e.g., no arrhythmias or discontinuous ventilation, after 20 and 60 min). Exposure to $10^{-4} \mathrm{M} \mathrm{OA}$ and $10^{-3} \mathrm{M}$ OA for $20 \mathrm{~min}$ significantly accelerated the rhythm (one-way RM-ANOVA; $F=$ 5.026; $\mathrm{df}=5 ; p<0.05$ ) (Table 1). EP had no effect on rhythm generation (no arrhythmias or discontinuous ventilation) and had no effect on ventilatory rhythm frequency (Table 1). After HS or $1 \mathrm{~h}$ exposures to $10^{-4} \mathrm{M} \mathrm{OA}, \mathrm{DA}, \mathrm{TA}$, or $10^{-6} \mathrm{M} \mathrm{EP}$, there were no significant differences in ventilatory frequency (Table 1 ).

\section{HS and octopamine increase the upper thermal limit for pattern generation}

Ventilatory motor pattern frequency increased from $\sim 1$ to $3 \mathrm{~Hz}$ as thoracic temperature was ramped from $20^{\circ} \mathrm{C}$ to failure $(\sim 38-$ $45^{\circ} \mathrm{C}$ ) (Figs. $2 A, B, 3$, top). During the temperature ramp, the duration of expiratory bursts recorded from muscle 161 decreased from $250-350$ to $\leq 100 \mathrm{~ms}$ before pattern failure (Figs. $2 A, C, 3$, middle), whereas duty cycle did not change (Figs. $2 A, D$, 3 , bottom). Below the point of failure, there were no significant differences in motor pattern frequency, expiratory burst duration, or duty cycle between Con, HS, and OA-injected animals as temperature was raised. However, the prevalence of arrhythmias at elevated temperatures was greater in Con and epinastineinjected HS locusts (EP-HS) (65 and 60\%) and lower in HS and OA-injected animals (40 and 25\%), suggesting a rhythmstabilizing effect of OA and HS treatments at high temperatures (Fig. $4 \mathrm{~B}$ ). Also, HS and OA preparations continued to operate at higher temperatures than Con preparations (Fig. 2) as indicated by the extension of the temperature relationships into the $40-$ $45^{\circ} \mathrm{C}$ bin (Fig. 3 ).

To confirm that failure of pattern generation measured at the periphery was not a result of axonal conduction failure in the nerve roots or the failure of neuromuscular transmission, we recorded intracellularly from pattern-generating interneurons in the MTG during temperature ramps (Fig. 5). Identification was made on the basis of membrane potential oscillation in phase with the ventilatory electromyogram, supporting high-frequency bursts of action potentials and an ability to modify the rhythm when stimulated (data not shown). For seven of seven such recordings, central failure was exactly coincident with failure of the EMG recording (Fig. 5). For five of the seven recordings, failure was associated with subsequent depolarization of the neuron. 


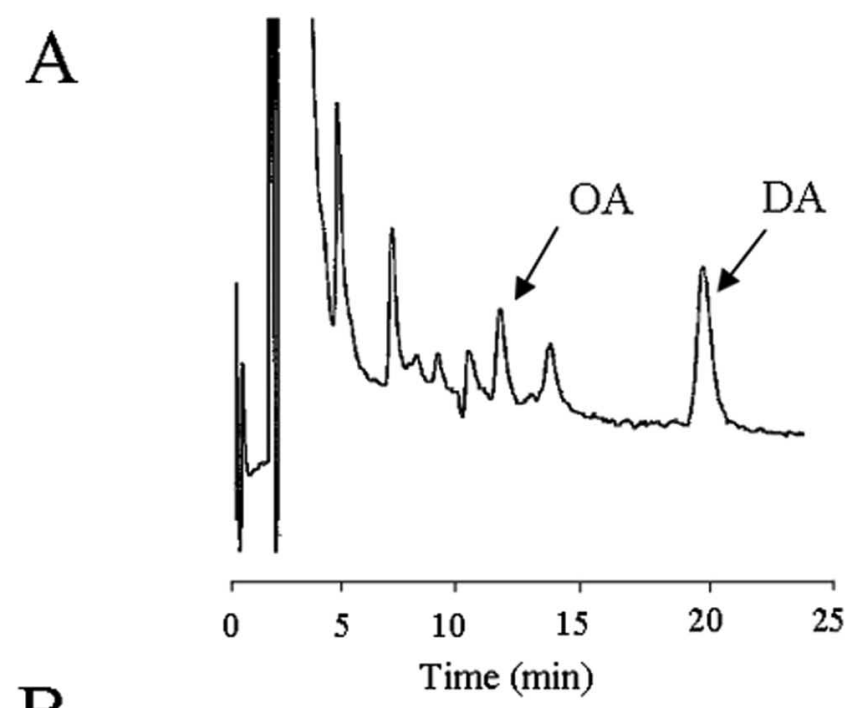

B

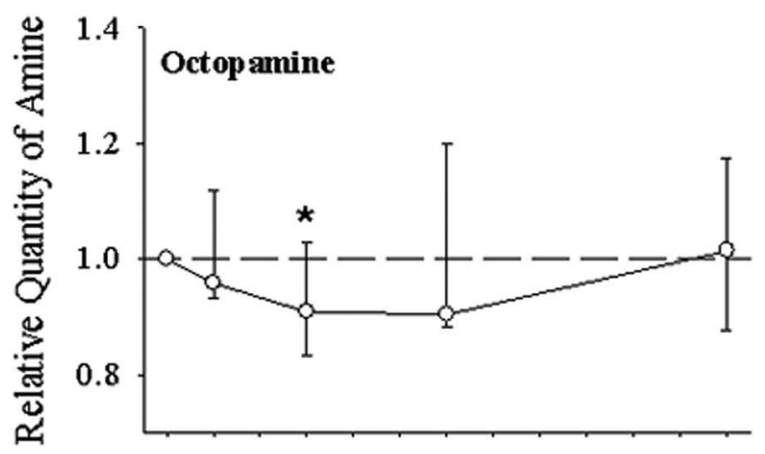

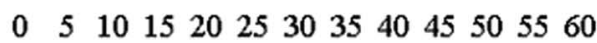

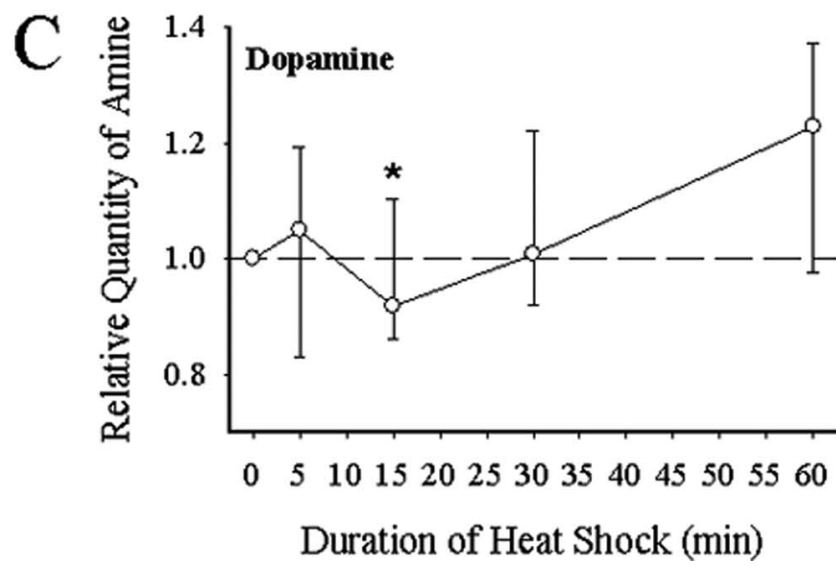

Figure 1. HPLC for octopamine and dopamine. A, Typical chromatogram of MTG tissue from a male locust, showing the octopamine peak at $11.27 \mathrm{~min}$ and the dopamine peak at $19.89 \mathrm{~min}$. See Materials and Methods for details of procedure. $\boldsymbol{B}$, Relative levels of OA in the MTG at different times after the start of heat shock $\left(45^{\circ} \mathrm{C}\right)$. C, Relative levels of DA in the MTG at different times after the start of heat shock. Note the significant transient decrease in ganglionic content of both amines after $15 \mathrm{~min}$ of HS. Levels were recovered after $60 \mathrm{~min}$. HS samples were run paired with Con samples allowing the HS level to be normalized to the Con in the pair. Data are plotted as median and quartiles. The dashed line at 1 indicates no change relative to control, and asterisks indicate significant difference from control. Sample sizes: $0 \mathrm{~A}, n_{5 \mathrm{~min}}=8, n_{15 \mathrm{~min}}=14$, $n_{30 \min }=7, n_{60 \min }=9 . D A, n_{5 \min }=8, n_{15 \text { min }}=14, n_{30 \text { min }}=7, n_{60 \text { min }}=7$.

\section{Neurohormonal effects of octopamine mediate} ventilatory thermotolerance

To test whether acute OA treatment could generate thermotolerance, short bath applications of $20 \mathrm{~min}$ were given and compared
Table 1. Aminergic- and EP-induced changes in motor pattern frequency after various exposure lengths

\begin{tabular}{lll}
\hline & \multicolumn{2}{l}{ Frequency $(\mathrm{Hz})$} \\
\cline { 2 - 3 } Treatment & 20 min exposure & 60 min exposure \\
\hline Con & $0.99 \pm 0.05(21)$ & $0.96 \pm 0.05(21)$ \\
HS & $1.07 \pm 0.04(17)$ & $1.02 \pm 0.06(15)$ \\
DA $10^{-4} \mathrm{M}$ & Not tested & $0.85 \pm 0.09(10)$ \\
TA $10^{-4} \mathrm{M}$ & Not tested & $0.92 \pm 0.08(10)$ \\
OA $10^{-5} \mathrm{M}$ & $1.14 \pm 0.08(8)$ & Not tested \\
OA $10^{-4} \mathrm{M}$ & $1.21 \pm 0.06(8)^{*}$ & $1.09 \pm 0.06(13)$ \\
OA $10^{-3} \mathrm{M}$ & $1.28 \pm 0.06(8)^{*}$ & Not tested \\
EP $10^{-6} \mathrm{M}$ & $0.89 \pm 0.06(10)$ & $0.90 \pm 0.05(10)$ \\
\hline
\end{tabular}

Values are mean $\pm \operatorname{SE}(n)$. The asterisk indicates significant differences from Con $(p<0.05)$.

with Con and HS preparations. The temperature at which the ventilatory motor pattern failed was significantly increased by HS treatment but was unaffected by short $20 \mathrm{~min}$ bath applications of OA at both $10^{-4} \mathrm{M}$ and $10^{-3} \mathrm{M}$ (Fig. 6A) $\left(10^{-3} \mathrm{M}\right.$ data not shown; one-way RM-ANOVA, $F=6.775$; $\mathrm{df}=12 ; p=0.007)$. HS animals recovered ventilation significantly faster than Con animals (one-way RM-ANOVA; $F=5.281 ; \mathrm{df}=12 ; p=0.015$ ), but recovery time in OA-treated (both concentrations) animals and Con were not different from one another (Fig. 6B) (data for $10^{-3} \mathrm{M}$ not shown). Similar OA treatment on HS preparations had no significant effect (data not shown).

Extended $(1 \mathrm{~h})$ bath applications of $10^{-4} \mathrm{M} \mathrm{OA}$ induced thermotolerance of the neural circuitry coordinating ventilation similar to a HS treatment, whereas $10^{-4} \mathrm{M}$ TA did not (Fig. 6C,D). Failure temperatures for OA and HS groups were significantly higher than Con and TA (one-way RM-ANOVA, $F=7.416$; $\mathrm{df}=$ $3 ; p=0.001$; Tukey's test, $p=0.05$ ) (Fig. $6 C$ ). The length of time taken to recover motor pattern function was also significantly shorter in HS and OA compared with Con and TA groups (oneway RM-ANOVA, $F=8.854 ; \mathrm{df}=3 ; p=0.001$; Tukey's test, $p<$ 0.05) (Fig. 6D).

To test longer exposures to amines, injections $(2 \mu \mathrm{g} / \mu \mathrm{l})$ of OA, DA, or EP into the hemocoel were made $4-8 \mathrm{~h}$ before thermotolerance testing. There were significant differences in the level of thermotolerance (failure temperature, one-way RMANOVA, $F=4.430, \mathrm{df}=4, p=0.004$; recovery time, one-way RM-ANOVA, $F=6.059$, df $=4, p=0.001)$. We found HS failure temperatures to be significantly higher (Tukey's test; $p<0.05$ ) than all groups except for OA-injected animals (Fig. 6E). Furthermore, failure temperatures for OA-injected animals were significantly higher than Con and epinastine-injected HS locusts (EP-HS) (Tukey's test; $p=0.01$ ) (Fig. 6E). No significant differences in failure temperatures were found between Con, DA, and EP-HS groups. Recovery time was significantly different between groups (one-way RM-ANOVA; $F=6.059$; $\mathrm{df}=4 ; p=0.001$ ) (Fig. $6 F$ ). Both HS- and OA-injected locusts recovered ventilation significantly faster than Con, EP-HS, and DA groups (Tukey's test; $p=0.05$ ). In separate experiments, EP was injected into control locusts. These animals had failure temperatures and recovery times of $40.7 \pm 2.1^{\circ} \mathrm{C}$ and $183 \pm 38 \mathrm{~s}$ and were not significantly different from the sham-injected Con group. We also tested to determine whether recovery of thermoprotection could be achieved in EP-injected control animals with a bath application of $10^{-4} \mathrm{M}$ OA for $1 \mathrm{~h}$. We found no increase in failure temperature; it was slightly lower than controls $(36.2 \pm 1.8$ vs $37.4 \pm 1.0^{\circ} \mathrm{C}$ ), suggesting a persistent block of Oct $\beta$ Rs by EP. Recovery time was significantly increased in EP-injected control animals when compared with the control group (234 \pm 48 vs $143 \pm 22 \mathrm{~s}$; $t$ test, $p=0.05$ ). 
Octopamine-mediated thermotolerance depends on the cAMP/PKA pathway After elevating cAMP levels with a $1 \mathrm{~h}$ bath application of $10^{-5} \mathrm{M}$ FOR, we found a significant difference in failure temperature between treatments (one-way RMANOVA; $F=5.162 ; \mathrm{df}=2 ; p=0.015$ ) (Fig. 7A). HS- and FOR-treated locusts had significantly higher failure temperatures than the Con group (Tukey's test; $p<0.010)$. Furthermore, significant differences were found in recovery time (one-way RM-ANOVA; $F=7.107$; $\mathrm{df}=2$; $p=0.004$ ) (Fig. $7 B$ ). After FOR treatment, we found motor pattern recovery time to be significantly shorter than controls (Tukey's test; $p=0.005$ ).

Neuropil injections of Sp-cAMPs (PKA agonist) or Rp-cAMPs (PKA antagonist) led to significant differences in both failure temperatures (one-way RMANOVA; $F=5.590$; $\mathrm{df}=3 ; p=0.003$ ) (Fig. $8 A$ ) and recovery times (one-way RM-ANOVA; $F=5.846 ; \mathrm{df}=3 ; p=$ 0.002 ) (Fig. $8 B$ ) of the motor pattern. After injections of Sp-cAMPs, the ventilatory neural circuitry had significantly higher failure temperatures (Tukey's test; $p=$ $0.011)$ and shorter recovery times (Tukey's test; $p=0.061$ ) than controls (Fig. $8 A, B$ ). Furthermore, by bath applying OA while injecting Rp-cAMPs into the neuropil, we observed a significant reduction in the level of thermoprotection conferred by OA (Fig. $8 A, B$ ). Failure temperatures were significantly increased (Tukey's test; $p=0.093$ ), and recovery times were significantly decreased (Tukey's test; $p=0.022$ ) when compared with OA-treated locusts. Failure temperatures and recovery times of locusts injected with saline into the neuropil while concurrently giving a $1 \mathrm{~h}$ bath application of $10^{-4} \mathrm{M} \mathrm{OA}$ and locusts that received injections of Sp-cAMPs were not significantly different from one another (failure temperature, Tukey's test, $p=0.697$; recovery time, Tukey's test, $p=0.938$ ). In addition, we found that thermoprotection could be rescued in EP-HS locusts by bypassing the receptor and directly activating the pathway with Sp-cAMPs (Fig. 8C,D). Failure temperatures in these animals were significantly higher than those of HS locusts treated with epinastine (Tukey's test; $p=0.037$ ). Recovery time was reduced in these animals when compared with EP-HS locusts (Tukey's test; $p=0.126$ ).

\section{Octopamine-mediated thermotolerance requires protein synthesis}

We examined the effects of blocking transcription and translation during bath application of OA. Locusts that receive neuropil injections of ACTD while being bathed in OA had significantly reduced failure temperatures (Tukey's test; $p=0.032$ ) and took a significantly longer time to recover (Tukey's test; $p=0.10$ ) after heat-induced failure of the CPG (Fig. 9A,B) than OA-treated animals. Similarly, locusts that received neuropil injections of $\mathrm{CHX}$ while being bathed in OA had reduced failure temperatures
Con $\mathrm{HS} \quad \mathrm{OA}$
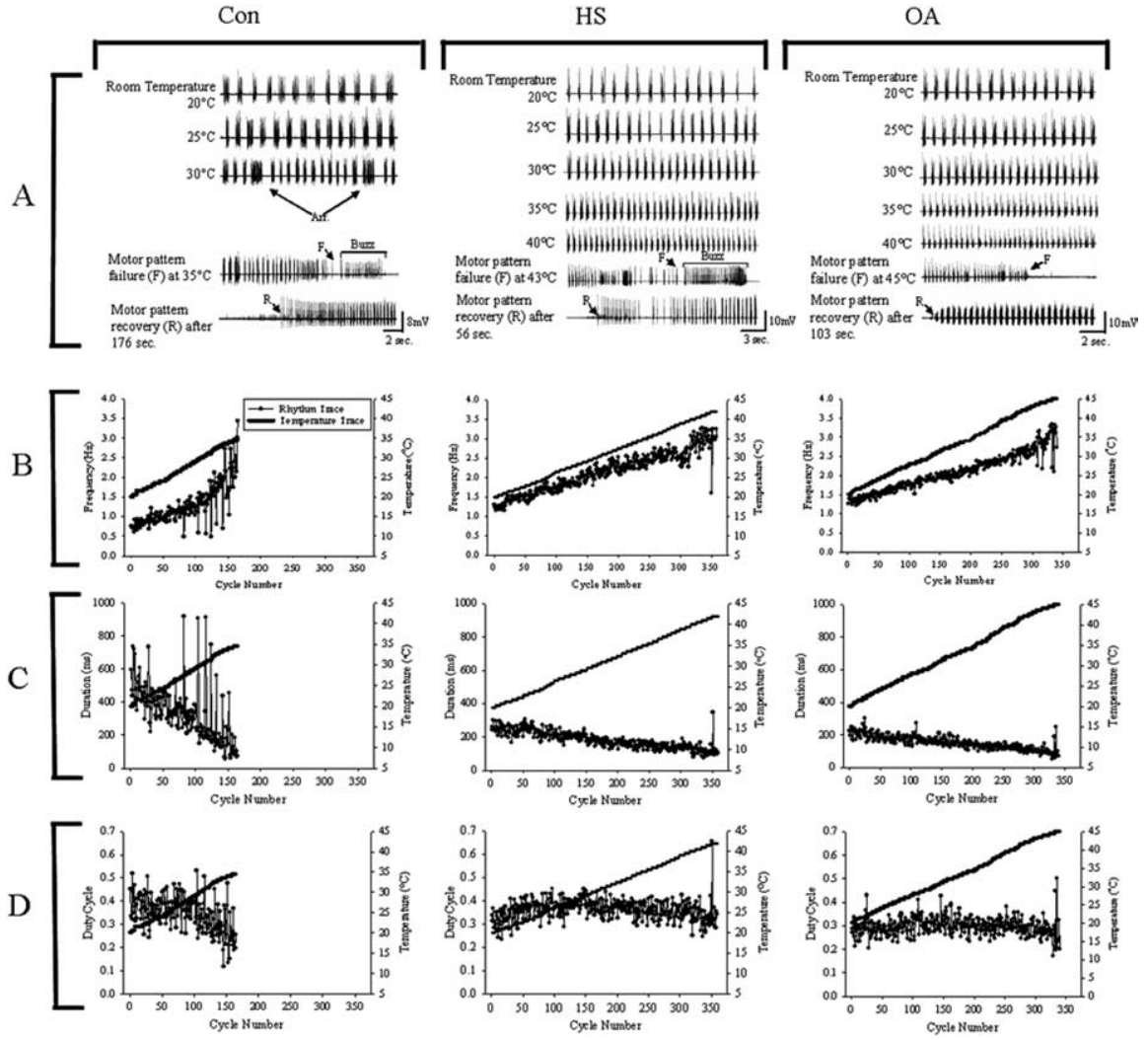

Figure 2. Ventilatory motor pattern activity in control (Con; left column), heat shock-treated (HS; middle column), and Duty cycle plotted against cycle number during the temperature ramp. Arrhythmias in Con preparations are evident as single cycle decreases in motor pattern frequency and increases in expiratory burst duration and duty cycle.

(Tukey's test; $p=0.009$ ) and took longer to recover (Tukey's test; $p=0.08)$ than locusts treated with OA (Fig. $9 A, B)$.

\section{Octopamine and HS both increase motor pattern recovery} rates after injection of $\mathrm{K}^{+}$into the ventilatory neuropil Hyperthermic failure of motor pattern generation is coincident with a rapid rise in extracellular $\left[\mathrm{K}^{+}\right]$, and recovery is reliably correlated with clearance of this load (Robertson, 2004). We measured the length of time taken to reestablish motor pattern operation after injections of locust saline containing high levels of $\mathrm{K}^{+}$(150 mM vs $\left.10 \mathrm{~mm}\right)$. In all experiments, motor pattern operation was arrested by this treatment. The length of time taken to recover motor pattern operation after injections was significantly different between groups (RM-ANOVA; $F=6.768$; $\mathrm{df}=3 ; p=0.001)$. OA- and HS-treated locusts were able to recover motor pattern function significantly faster than Con and EP-HStreated locusts (Tukey's test; $p<0.08$ ) (Fig. 10).

\section{Discussion}

In its semi-arid habitat of Asia and Africa, L. migratoria is exposed to an average air temperature of $32^{\circ} \mathrm{C}$ with temperatures reaching $55^{\circ} \mathrm{C}$ during the hottest periods of the day (Uvarov, 1977). Excess heat gained through metabolism, substrate conduction, and radiant energy from the sun drives internal temperatures of the locust well above ambient levels (Uvarov, 1966). In response to these harsh challenges, locusts have evolved physiological mech- 

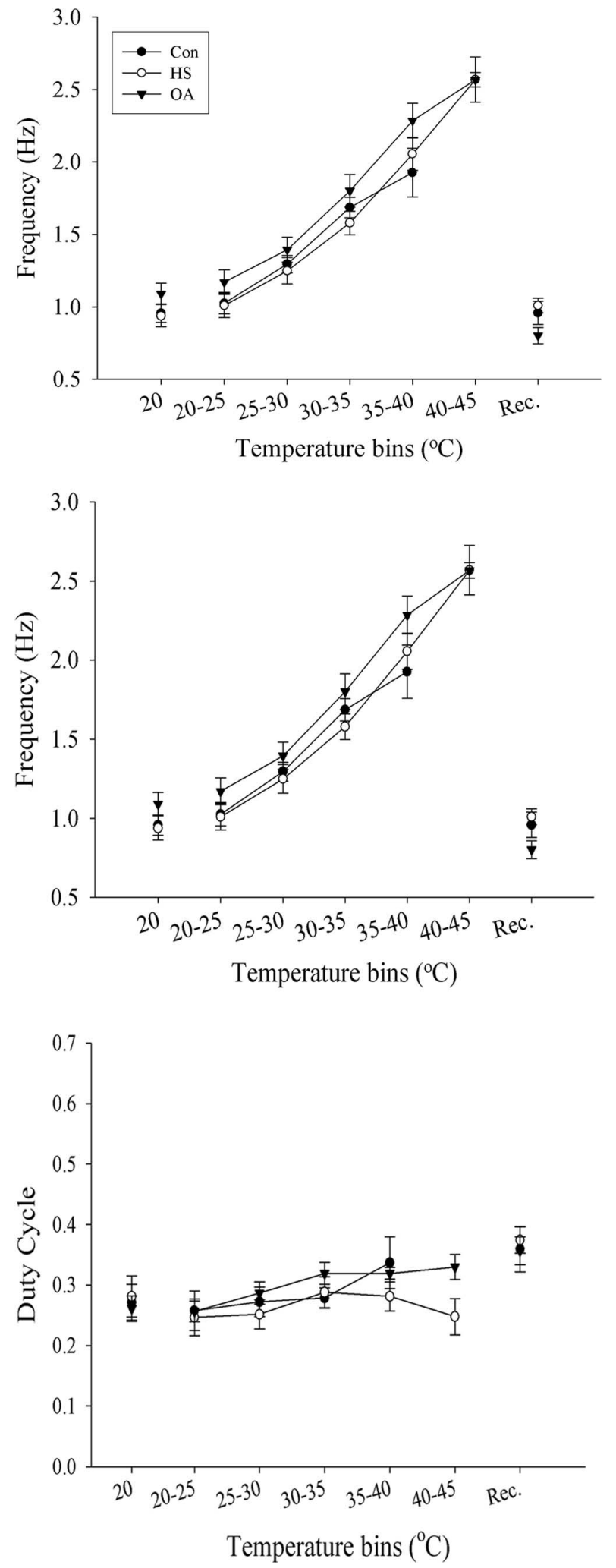

Figure 3. Motor pattern parameters during temperature ramps in Con, $\mathrm{HS}$, and OA preparations. Top, Relationship between motor pattern frequency and temperature. Frequency increases as temperature is raised. Middle, Expiratory burst duration decreases as temperature is raised. Bottom, Duty cycle remains unchanged by the rise in temperature. Values for each parameter were averaged within each $5^{\circ} \mathrm{C}$ temperature bin and plotted as mean \pm SE. Note that $\mathrm{HS}$ and $\mathrm{OA}$ relationships have values at $40-45^{\circ} \mathrm{C}$, whereas Con relationships terminate at $35-40^{\circ} \mathrm{C}$. Values before and after the temperature ramp are presented as $20^{\circ} \mathrm{C}$ and after motor pattern recovery (Rec.). Sample sizes: Con, $n=13 ; \mathrm{HS}, n=10 ; 0 \mathrm{~A}, n=11$. Error bars represent mean \pm SE.
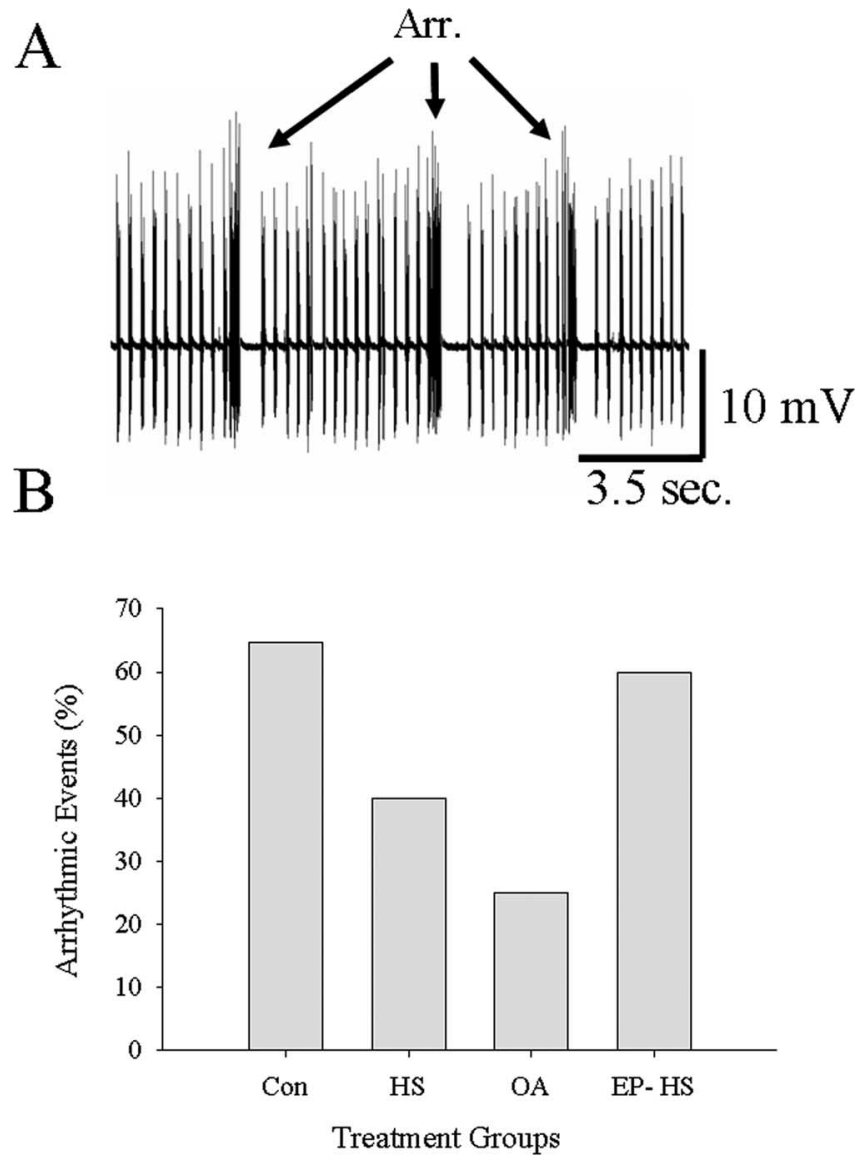

Figure 4. Frequency of occurrence of ventilatory arrhythmias. $A$, Electromyographic trace of expiratory muscle 161 with three successive arrhythmias (Arr.). $B$, The frequency of occurrence (\%) of locusts having at least 1 arrhythmic event in Con, $\mathrm{HS}, \mathrm{OA}$, and EP-HS preparations. Note fewer arrhythmias in $\mathrm{HS}$ and $\mathrm{OA}$ compared with Con and EP-HS locusts.

anisms to cope with extreme temperatures. HS preconditioning confers subsequent protection of the locust nervous system from hyperthermic stress (Robertson et al., 1996; Barclay and Robertson, 2000). We demonstrate here that OA is the crucial endogenous ligand that signals neural tissue to switch on protective physiological adaptations that provide thermotolerance.

We used ventilation, a vital motor activity controlled by neural circuitry in the MTG as our model system for investigating the thermoprotection of circuit function. The ventilatory CPG, like all insect neural circuits, is sensitive to temperature change, and as body temperature rises, neural activity increases. Ventilatory rhythm frequency increases and expiratory burst duration decreases as temperature of the MTG rises, whereas duty cycle remains stable throughout temperature change. At some point during a temperature ramp, thermal stress exceeds the physiological mechanisms that allow ventilatory rhythm generation to operate and ventilation fails. In our semi-intact preparation, ventilatory motor pattern operation failed at $38-40^{\circ} \mathrm{C}$ in control animals and $44-45^{\circ} \mathrm{C}$ in $\mathrm{HS}$ preconditioned animals. Locusts treated with OA had failure temperatures between 43 and $44^{\circ} \mathrm{C}$, whereas neither DA $\left(40^{\circ} \mathrm{C}\right)$ nor $\mathrm{TA}\left(39^{\circ} \mathrm{C}\right)$ generated thermoprotection. In addition to extension of the upper thermal limit, recovery of CPG function after temperature-induced failure was more than twice as fast in animals that had received HS or OA treatment. The most conclusive evidence we have that $\mathrm{OA}$ is signaling neural tissue to switch on a thermoprotective response during HS treatment is that blocking effects of endogenous $\mathrm{OA}$ with epinastine, a highly 

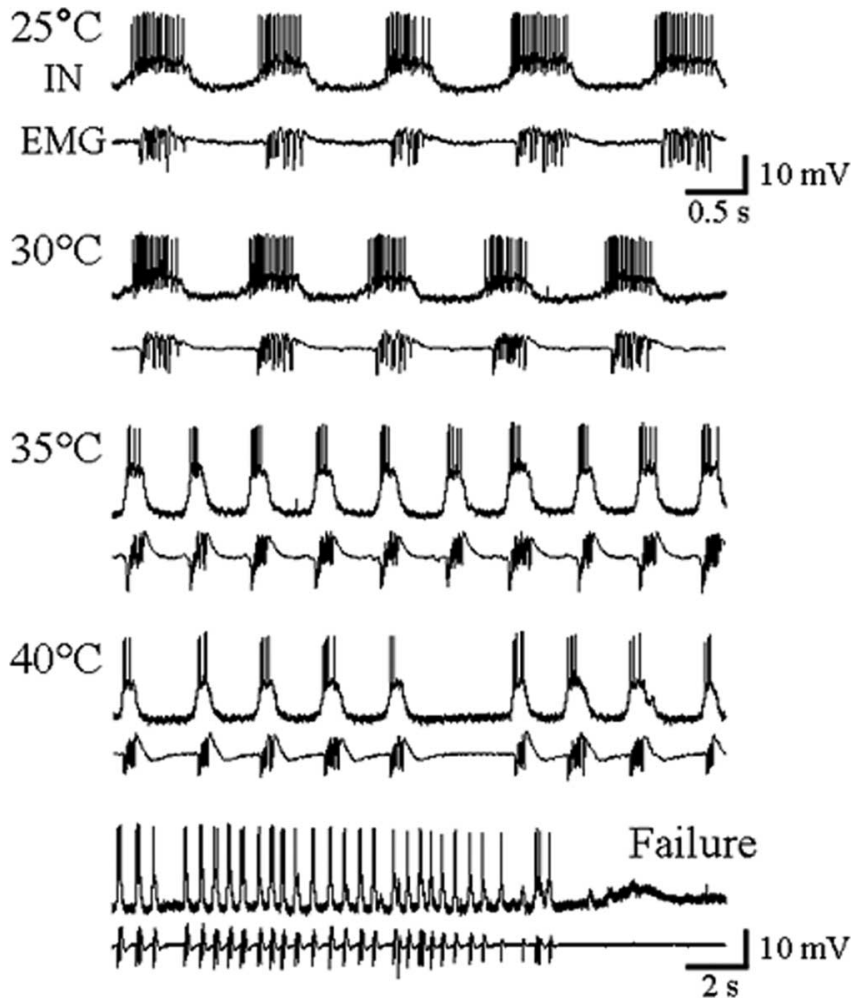

Figure 5. Failure of central pattern generation. Intracellular recording (IN) of a ventilatory interneuron (top trace) and electromyogram of expiratory muscle 161 (bottom trace) during a temperature ramp to failure. The rhythm frequency increases with temperature, with fewer interneuronal spikes per cycle. Note the arrhythmia at $40^{\circ} \mathrm{C}$, and that failure monitored electromyographically was coincident with failure of the CPG. The bottom panel has a different time scale.

selective and potent antagonist of locust Oct $\beta$ Rs (Roeder et al., 1998), abolished the protective changes, which are normally acquired during HS.

Using HPLC to measure ganglionic OA concentrations during heat stress, we observed a modest drop in content of OA after $15 \mathrm{~min}$ before returning to normal levels after $30 \mathrm{~min}$. Although this drop in OA is likely a result of OA being released into peripheral and central sites such as the ventilatory neuropil, we cannot rule out the possibility that during heat stress, there is a reduction in OA synthesis or increase in its metabolism. We confirmed the direct excitatory actions of OA on the ventilatory CPG (Sombati and Hoyle, 1984; Ramirez and Pearson, 1989). Exposures to short (20 min) bath applications of OA resulted in increased motor pattern frequency. Furthermore, treatment with epinastine was sufficient to block the excitatory effects of $\mathrm{OA}$ on the ventilatory rhythm. In locusts, hemolymph OA concentrations more than double after exposures to heat stress (Davenport and Evans, 1984). The source of increased hemolymph OA is probably from ganglionic OA-immunoreactive dorsal unpaired median and ventral unpaired median neurons of the ventral ganglia (Stevenson and Spörhase-Echmann, 1995; Duch et al., 1999; Bräunig and Burrows, 2004). The vast majority of these neurons have peripheral release sites, although central release sites for OA in the MTG have been reported (Watson, 1984). We suggest that these central release sites modulated the ventilatory CPG during times of stress.

In the insect CNS, Oct $\beta$ Rs are coupled to adenylyl cyclase (Evans and Maqueira, 2005; Maqueira et al., 2005). After activation of these receptors, $[\mathrm{cAMP}]_{\mathrm{i}}$ rises in the CNS and epinastine blocks this rise in $[\mathrm{cAMP}]_{\mathrm{i}}$ (Roeder et al., 1998). Increased adeny-
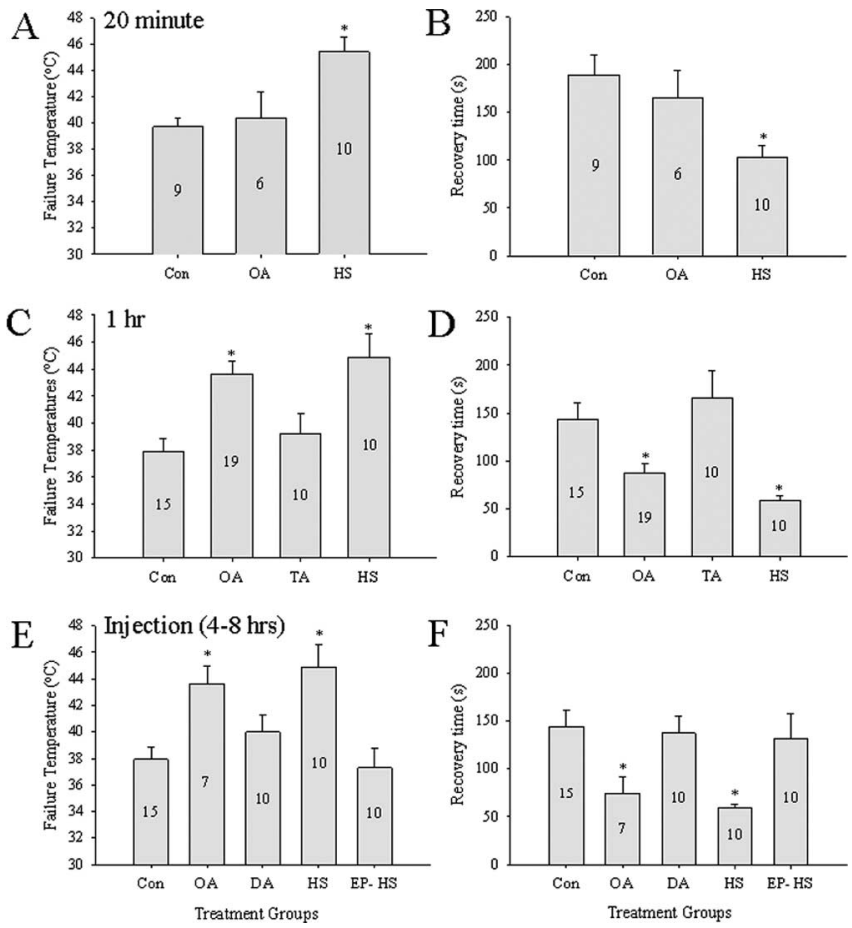

Figure 6. Ventilatory thermotolerance measured by failure temperature $(A, C, E)$ and recovery time $(\boldsymbol{B}, \boldsymbol{D}, \boldsymbol{F}) \cdot \boldsymbol{A}, \boldsymbol{B}$, Thermotolerance induced by $\mathrm{HS}$ but not by $20 \mathrm{~min}$ bath applications of $10^{-4} \mathrm{M} \mathrm{OA}$. C, $\boldsymbol{D}$, Thermotolerance induced by $\mathrm{HS}$ and by $1 \mathrm{~h}$ bath application of $10^{-4} \mathrm{M} \mathrm{OA}$ but not by $1 \mathrm{~h}$ bath application of $10^{-4} \mathrm{M} \mathrm{TA}$. E, $\boldsymbol{F}$, Thermotolerance induced by $\mathrm{HS}$ and by injection of $O \mathrm{~A}(2 \mu \mathrm{g} / 10 \mu \mathrm{l})$ into the hemocoel of intact animals $4-8 \mathrm{~h}$ before testing. Similar injections of DA were ineffective. Injections of EP to block $0 \mathrm{ct} \beta$ Rs abolished the effect of HS (HS-EP). Con and $\mathrm{HS}$ animals received sham injections of the same volume of locust saline. Numbers in the bars indicate sample sizes. Asterisks indicate significant differences from Con $(p<0.05)$. Error bars represent mean $\pm \mathrm{SE}$.
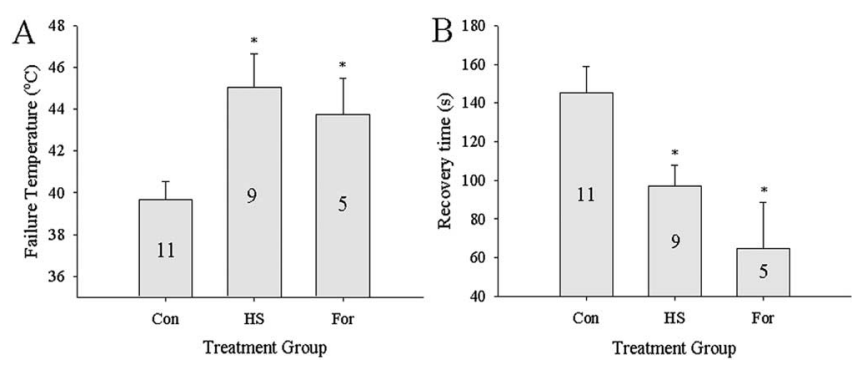

Figure 7. Activation of adenylyl cyclase via bath application (1 $\mathrm{h}$ ) of $10^{-5} \mathrm{M}$ For mimics $\mathrm{HS}$. $\boldsymbol{A}$, Failure temperature. $\boldsymbol{B}$, Recovery time. Numbers in the bars indicate sample sizes. Asterisks indicate significant differences from Con $(p<0.05)$. Error bars represent mean $\pm \mathrm{SE}$.

lyl cyclase activity after a $1 \mathrm{~h}$ forskolin application increased motor pattern thermotolerance in our experiments. To further confirm the role cAMP plays in protecting the CNS, we used a pressure injection system to deliver nanolitres of an agonist or antagonist directly into the ventilatory neuropil over a $1 \mathrm{~h}$ period. Injections of the membrane-permeable cAMP analog and PKA activator Sp-cAMPs (Wang et al., 1991), protected the ventilatory CPG. Failure temperatures were $6^{\circ} \mathrm{C}$ higher, and the $\mathrm{CPG}$ recovered its function 2 min faster than in control preparations. In addition, injections of Sp-cAMPs into epinastine-treated HS locusts restored thermoprotection, although Oct $\beta$ Rs were blocked. Using the potent competitive inhibitor of cAMP-PKA-mediated effects, Rp-cAMPs (Botelho et al., 1988; Wang et al., 1991; Widmer et al., 2005), we were able to abolish the thermoprotective 

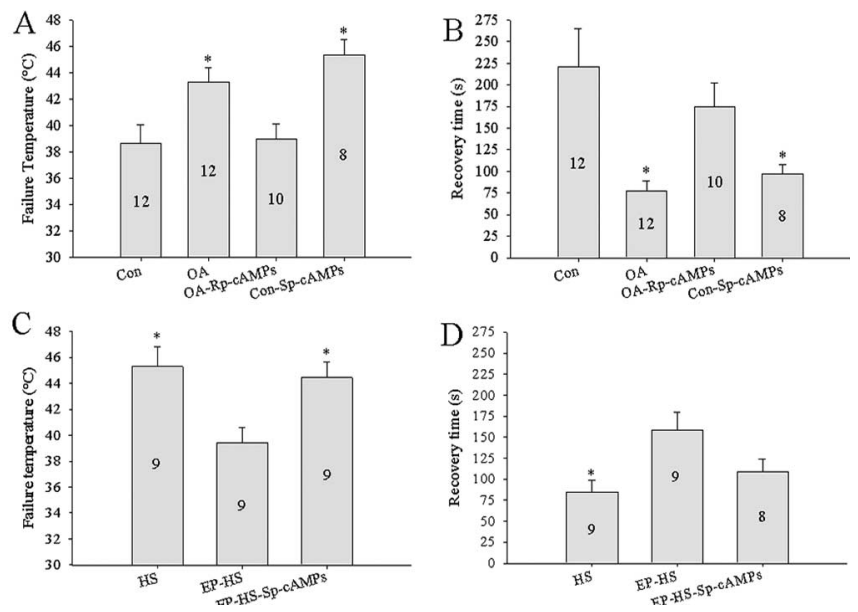

Figure 8. Activating the PKA pathway mimics HS. $A, B$, Thermotolerance induced via injections $(70 \mathrm{nl})$ of the CAMP analog Sp-CAMPs into the ventilatory neuropil over $1 \mathrm{~h}$ (Con-Sp(AMPs). Thermotolerance induced by $1 \mathrm{~h}$ bath application of $10^{-4} \mathrm{M} O \mathrm{~A}$ was abolished via injections of Rp-CAMPs (OA-Rp-CAMPs). Con and OA preparations received sham injections of locust saline. C, D, Thermotolerance was recovered in $\mathrm{HS}$ locusts treated with the 0ct $\beta$ Rs antagonist epinastine by neuropil injection of Sp-cAMPs. Numbers in the bars indicate sample sizes for each group. Asterisks indicate significant differences from Con and OA-Rp-CAMPs in $A$ and $\boldsymbol{B}$ and EP-HS in $\boldsymbol{C}$ and $\boldsymbol{D}(p<0.05)$. Error bars represent mean \pm SE.
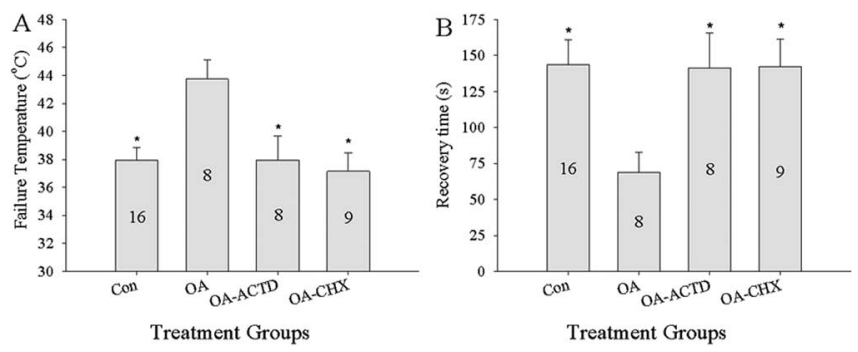

Figure 9. Octopamine-mediated thermotolerance is dependent on protein synthesis. Injections of actinomycin D (OA-ACTD) a transcription inhibitor, or cycloheximide (OA-CHX), a translation inhibitor, into the ventilatory neuropil abolished the effect of bath application of $10^{-4} \mathrm{M}$ $0 \mathrm{~A}$ for $1 \mathrm{~h}(0 \mathrm{~A}) . \boldsymbol{A}$, Failure temperature. $\boldsymbol{B}$, Recovery time. Con and $0 \mathrm{~A}$ preparations received sham injections. Numbers in the bars indicate sample sizes. Asterisks indicate significant differences from $0 \mathrm{~A}$-treated animals $(p<0.05)$. Error bars represent mean $\pm \mathrm{SE}$.

effects of OA treatment. Thus, we have shown that raising cAMP levels and activating PKA mimics the effects of a previous HS, whereas reducing CAMP/PKA-mediated effects attenuates the ability of the circuit to cope with thermal stress.

Increased intracellular levels of cAMP have been noted to regulate $\mathrm{K}^{+}$channel activity (Goldsmith and Abrams, 1992; Yuan et al., 2002). We have shown that decreased $\mathrm{K}^{+}$channel activity has protective effects ( $\mathrm{Wu}$ et al., 2001), and after HS, whole-cell patch-clamp recordings from neurons of the MTG show reduced $\mathrm{K}^{+}$currents (Ramirez et al., 1999). The reduction in $\mathrm{K}^{+}$currents may be mediated by OA, which is known to reduce resting $\mathrm{K}^{+}$ conductance in locusts (Walther and Zittlau, 1998). $\mathrm{K}^{+}$channel downregulation may delay the build up in $\left[\mathrm{K}^{+}\right]_{\mathrm{o}}$ at high temperatures, but another crucial step in protecting the CNS would be the ability to clear excess extracellular potassium. Thus, modulation of the $\mathrm{Na}^{+} / \mathrm{K}^{+}$ATPase pump and/or $\mathrm{K}^{+} / \mathrm{Na}^{+} / 2 \mathrm{Cl}^{-}$cotransporter activity could be involved in HS-mediated thermotolerance. OA stimulates the activity of the $\mathrm{Na}^{+} / \mathrm{K}^{+}$ATPase pump in locust muscle tissue (Walther and Zittlau, 1998) and regulates glia-specific pumps on the sheath of the thoracic ganglia, which have been shown to regulate potassium permeability
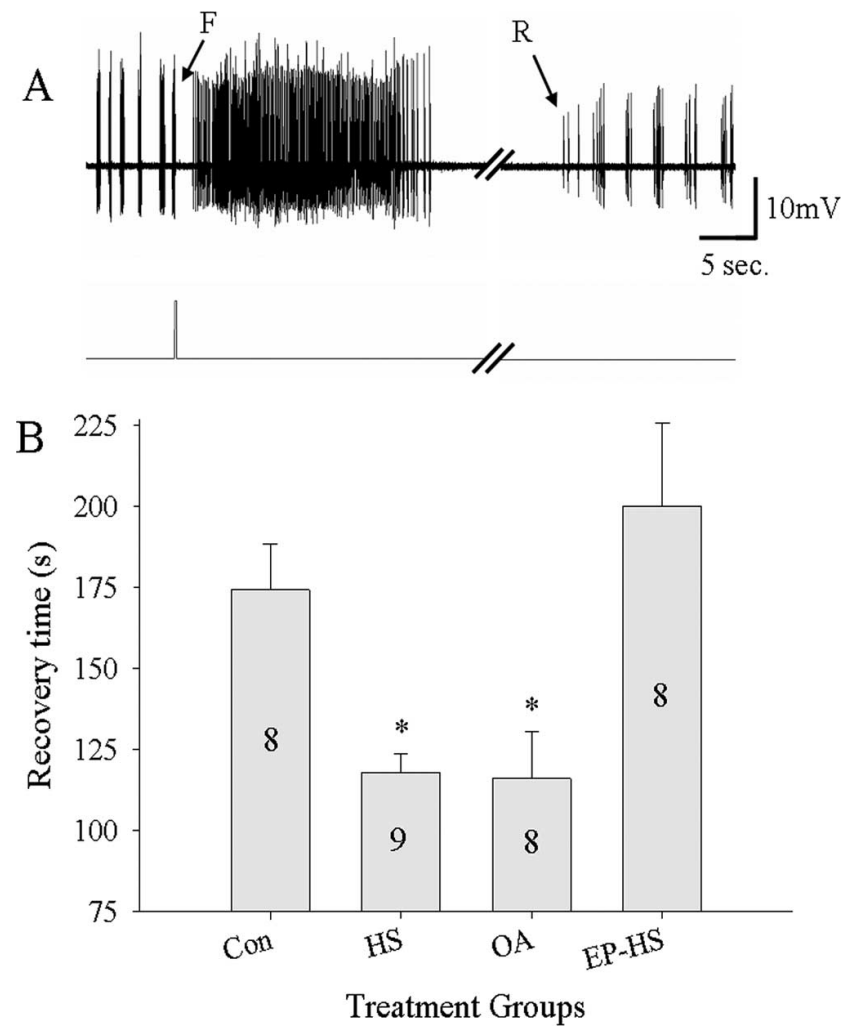

Figure 10. Octopamine treatment and $\mathrm{HS}$ increases speed of motor pattern recovery after $\mathrm{K}^{+}$injection. A, Electromyogram of activity in expiratory muscle 161 (top trace) after injection of saline containing high $\mathrm{K}^{+}$( 150 vs $10 \mathrm{~mm}$ ) into the ventilatory neuropil (timing indicated in bottom trace). Note termination of ventilatory rhythm generation (F) associated with a burst of unpatterned activity and subsequent recovery $(R) . B$, Recovery time was shorter in $\mathrm{HS}$ and $\mathrm{OA}$ animals. Epinastine abolished the effect of HS (EP-HS). Numbers in the bars indicate sample sizes. Asterisks indicate significant differences from Con and EP-HS groups $(p<0.05)$. Error bars represent mean $\pm \mathrm{SE}$.

in cockroaches (Schofield and Treherne, 1985). Increased pump activity in neurons and glia after OA and HS treatments may account for the increase in motor pattern recovery rates after injections of high $\mathrm{K}^{+}$saline. It is interesting to note that HS and OA-treated animals have fewer instances of arrhythmias than Con and Ep-HS locust. The presence of hyperthermic arrhythmias could be attributed to neurons and glia, which are just beginning to lose their ability to maintain ionic gradients. The increased prevalence of ventilatory arrhythmias seen in animals that do not possess the physiological mechanisms to cope with thermal stress could be a result of poor $\left[\mathrm{K}^{+}\right]_{\mathrm{o}}$ handling at high temperatures.

Although ion channel and membrane pump regulation may play a major role in maintaining electrochemical homeostasis during times of increased stress, the plastic changes in potassium handling occurring after HS rely on a process that requires time to generate. We did not see a protective effect after $20 \mathrm{~min}$ bath applications of OA. Thus, it seems unlikely that the acute neuromodulatory effects of OA, which modulate channel and pump activity, play a role in generating a thermoprotected circuit. An alternative possibility is that $1 \mathrm{~h}$ bath applications of OA or injections into the hemocoel trigger the upregulation of heat shock proteins, notably HSP70 [requiring a similar length of time to be transcribed and translated (Whyard et al., 1986)], which in turn protect the operation of $\mathrm{K}^{+}$channels and the $\mathrm{Na}^{+} / \mathrm{K}^{+}$ATPase (Burdon and Cutmore, 1982; Armstead and Hecker, 2005; Riordan et al., 2005) at high temperatures. 
Although it has been postulated that OA may indirectly interact with the genome and increase synthesis of specific proteins (Roeder, 2005; Armstrong and Robertson, 2006) little evidence has been provided that this is the case. In this report, we show that the thermoprotective effects of OA treatment rely on gene transcription and translation. There are two plausible pathways for OA to interact with the genome and increase HSP levels. One mechanism would be through a cAMP-cAMP response elementbinding protein pathway (Roeder, 2005; Armstrong and Robertson, 2006). However, the primary induction pathway for HSPs is via heat shock transcription factor (HSF) binding to heat shock element, and it is more reasonable to assume that cAMP and PKA might help promote HSF binding to DNA. Previous reports support this claim, and Ohnishi et al. $(1998,1999)$ have shown that protein kinase inhibitors (staurosporine, $\mathrm{H} 7$, and combinations of calphostin and H89) suppressed heat-induced activation of HSF and HSP72 production.

HS preconditioning offers a protective change in the ability to handle subsequent thermal stress. The mechanisms for coordinating these changes after HS have remained elusive. We show here that a coordinated change in CNS physiology resulting in improved thermotolerance after HS preconditioning is mediated by octopamine activating a cAMP/PKA pathway and requires protein synthesis.

\section{References}

Armstead WM, Hecker JG (2005) Heat shock protein modulation of $\mathrm{K}_{\mathrm{ATP}}$ and $\mathrm{K}_{\mathrm{Ca}}$ channel cerbrovasodilation after brain injury. Am J Physiol Heart Circ Physiol 289:H1184-H1190.

Armstrong GAB, Robertson RM (2006) A role for octopamine in coordinating thermoprotection of an insect nervous system. J Therm Biol 31:149-158.

Barclay JW, Robertson RM (2000) Heat shock-induced thermoprotection of hindleg motor control in the locust. J Exp Biol 203:941-950.

Bellah KL, Fitch GK, Kammer AE (1984) A central action of octopamine on ventilation frequency in Corydalus cornutus. J Exp Zool 231:289-292.

Botelho LHP, Rothermel JD, Coombs RV, Jastorff B (1988) cAMP analog antagonist of cAMP action. Methods Enzymol 159:159-172.

Bräunig P, Burrows M (2004) Projection patterns of posterior dorsal unpaired median neurons of the locust subesophageal ganglion. J Comp Neurol 478:164-175.

Burdon RH, Cutmore CMM (1982) Human heat shock gene expression and the modulation of plasma membrane $\mathrm{Na}^{+}, \mathrm{K}^{+}$-ATPase activity. FEBS Lett 140:45-48.

Bustami HP, Hustert R (2000) Typical ventilatory pattern of the intact locust is produced by the isolated CNS. J Insect Physiol 49:1285-1293.

Davenport AP, Evans PD (1984) Stress-induced changes in the octopamine levels of insect haemolymph. Insect Biochem 14:135-143.

Duch C, Mentel T, Pflüger HJ (1999) Distribution and activation of different types of octopaminergic DUM neurons in the locust. J Comp Neurol 403:119-134.

Evans PD (1985) Octopamine. In: Comprehensive insect physiology, biochemistry, and pharmacology, Vol XI, Pharmacology (Kerkut GA, Gilbert LI, eds), pp 474-499. Oxford: Pergamon.

Evans PD, Maqueira B (2005) Insect octopamine receptors: a new classification scheme based on studies of cloned Drosophila G-protein coupled receptors. Invert Neurosci 5:111-118.

Goldsmith BA, Abrams TW (1992) cAMP modulates multiple $\mathrm{K}^{+}$currents, increasing spike duration and excitability in Aplysia sensory neurons. Proc Natl Acad Sci USA 89:11481-11485.

Kravitz EA, Huber R (2003) Aggression in invertebrates. Curr Opin Neurobiol 13:736-743.

Lange AE, Orchard I (1986) Identified octopaminergic neurons modulate contractions of locust visceral muscle via adenosine $3^{\prime}, 5^{\prime}$-monphosphate (cyclic AMP). Brain Res 363:340-349.

Maqueira B, Chatwin H, Evans PD (2005) Identification and characterization of a novel family of Drosophila $\beta$-adrenergic-like octopamine G-protein coupled receptors. J Neurochem 94:547-560.
Nathanson JA (1979) Octopamine receptors, adenosine $3^{\prime}, 5^{\prime}$-monophosphate, and neural control of firefly flashing. Science 28:254-268.

Newman AEM, Foerster M, Shoemaker KL, Robertson RM (2003) Stressinduced thermotolerance of ventilatory motor pattern generation in the locust, Locusta migratoria. J Insect Physiol 49:1039-1047.

Ohnishi K, Wang X, Takahashi A, Matsumoto H, Aoki H, Ohnishi T (1998) Effects of protein kinase inhibitors on heat-induced $h s p 72$ gene expression in a human glioblastoma cell line. Cell Signal 10:259-264.

Ohnishi K, Wang X, Takahashi A, Matsumoto H, Ohnishi T (1999) The protein kinase inhibitor, $\mathrm{H}-7$, suppresses heat induced activation of heat shock transcription factor 1. Mol Cell Biochem 197:129-135.

Orchard I (1982) Octopamine in insects: neurotransmitter, neurohormone, and neuromodulator. Can J Zool 60:659-669.

Orchard I, Loughton BG, Webb RA (1981) Octopamine and short-term hyperlipaemia in the locust. Gen Comp Endocr 45:175-180.

Ramirez JM, Pearson KG (1989) Alteration of the respiratory system at the onset of locust flight. J Exp Biol 142:401-424.

Ramirez JM, Elsen FP, Robertson RM (1999) Long-term effects of prior heat shock on neuronal potassium currents recorded in a novel insect ganglion slice preparation. J Neurophysiol 81:795-802.

Riordan M, Sreedharan R, Wang S, Thulin G, Mann A, Stankewich M, Van Why S, Kashgarian M, Siegel NI (2005) HSP70 binding modulates detachment of NA-K-ATPase following energy deprivation in renal epithelial cells. Am J Physiol Renal Physiol 288:F1236-F1242.

Robertson RM (2004) Thermal stress and neural function: adaptive mechanisms in insect model systems. J Therm Biol 29:351-358.

Robertson RM, Pearson KG (1982) A preparation for the intracellular analysis of neural activity during flight in the locust. J Comp Physiol 146:311-320.

Robertson RM, Xu H, Shoemaker KL, Dawson-Scully K (1996) Exposure to heat shock affects thermosensitivity of the locust flight system. J Neurobiol 29:367-383.

Roeder T (1999) Octopamine in invertebrates. Prog Neurobiol 59:533-561.

Roeder T (2005) Tyramine and octopamine: ruling behavior and metabolism. Annu Rev Entomol 50:447-477.

Roeder T, Degen J, Gewecke M (1998) Epinastine, a highly specific antagonist of insect neuronal octopamine receptors. Eur J Pharmacol 349:171-177.

Schofield PK, Treherne JE (1985) Octopamine reduces potassium permeability of the glia that form the insect blood-brain barrier. Brain Res 360:244-348

Sombati S, Hoyle G (1984) Generation of specific behaviors in a locust by local release into neuropil of the natural neuromodulator octopamine. J Neurobiol 15:481-506.

Stevenson PA, Spörhase-Echmann U (1995) Localization of octopaminergic neurons in insects. Comp Biochem Physiol B 110:203-215.

Uvarov B (1966) Grasshoppers and Locusts, a handbook of general acridology, Vol I. Cambridge, UK: Cambridge UP.

Uvarov B (1977) Grasshoppers and Locusts, a handbook of general acridology, Vol II. London: Centre of Overseas Pest Research.

Walther C, Zittlau KE (1998) Resting membrane properties of locust muscle and their modulation II. Actions of the biogenic amine octopamine. J Neurophysiol 80:785-797.

Wang LY, Salter MW, MacDonald JF (1991) Regulation of kainite receptors by cAMP-dependent protein kinase and phosphatases. Science 253:1132-1135.

Watson AHD (1984) The dorsal unpaired median neurons of the locust metathoracic ganglion: neuronal structures and diversity, and synaptic integration. J Neurocytol 13:303-327.

Whyard S, Wyatt GR, Walker VK (1986) The heat shock response in Locusta migratoria. J Comp Physiol B 156:813-817.

Widmer A, Höger U, Meisner S, French AS, Torkkeli PH (2005) Spider peripheral mechanosensory neurons are directly innervated and modulated by octopaminergic efferents. J Neurosci 25:1588-1598.

Wu BS, Walker VK, Robertson RM (2001) Heat shock-induced thermoprotection of action potentials in the locust flight system. J Neurobiol 49:188-199.

Yuan LL, Adams JP, Swank M, Sweatt JD, Johnston D (2002) Protein kinase modulation of dendritic $\mathrm{K}^{+}$channels in hippocampus involves a mitogen-activated protein kinase pathway. J Neurosci 22:4860-4868.

Zilberstein Y, Fuchs E, Hershtik L, Ayali A (2004) Neuromodulation for behavior in the locust frontal ganglion. J Comp Physiol A Neuroethol Sens Neural Behav Physiol 190:301-309. 